\title{
THEODICAL INDIVIDUALISM
}

\author{
T. J. MAWSON \\ University of Oxford
}

\begin{abstract}
In this journal Steve Maitzen has recently advanced an argument for Atheism premised on Theodical Individualism, the thesis that God would not permit people to suffer evils that were underserved, involuntary, and gratuitous for them. In this paper I advance reasons to think this premise mistaken.
\end{abstract}

I.

According to Jeff Jordan, 'Theodical Individualism asserts that God permits human persons to suffer only if "the sufferings of any particular person are outweighed by the good which the suffering produces for that person." He suggests the view enjoys 'prominent support' amongst philosophers of religion. Amongst those whom he cites as supporters, Eleonore Stump has given Theodical Individualism more precise shape in her claim, quoted by Jordan, that "if a good God allows evil, it can only be because the evil in question produces a benefit for the sufferer and one that God could not produce without the suffering."' I say 'more precise shape, as Stump's formulation brings out the fact that one sort of suffering the broader intuition behind Theodical Individualism suggests

${ }^{1}$ Jeff Jordan, International Journal for Philosophy of Religion 56: 169-178, (2004), p. 171-172. The philosophers he cites in support are Marilyn McCord Adams, Horrendous Evils and the Goodness of God (Ithaca, NY: Cornell University Press, 1999): pp. 29-31; William Rowe, 'The Empirical Argument from Evil' in Rationality, Religious Belief, \& Moral Commitment, pp. 244-245; Eleonore Stump, 'Providence and the Problem of Evil' in T. Flint, (ed.) Christian Philosophy, (Notre Dame, IN: University of Notre Dame Press, 1990): pp. 65-68; and Michael Tooley, 'The Argument from Evil' in J. Tomberlin (ed.), Philosophical Perspectives 5, Philosophy of Religion, (1991): pp. 110-111. The quotation from Stump comes from Eleonore Stump, 'The Problem of Evil' Faith and Philosophy 2(4) (1985), p. 411. 
God will not allow is that which whilst benefiting the sufferer more than it harms him or her is nevertheless gratuitous in the sense that the benefit could have been achieved in another way.

More recently, Stephen Maitzen, whilst dropping the notion of non-gratuity from his formulation, has still further specified Theodical Individualism with the claim that the category of suffering which it requires God to avoid permitting is only that which is involuntary on the part of the sufferer. As he puts it, 'Necessarily, God permits undeserved, involuntary human suffering only if such suffering ultimately produces a net benefit for the sufferer.' ${ }^{2}$ Maitzen makes his qualification of the principle because he sees 'nothing wrong with the idea of God's permitting undeserved suffering that people deliberately choose to endure for, say, the benefit of others without gaining for themselves a net benefit from it.' ${ }^{3}$ According to Maitzen then, God might allow undeserved suffering that is genuinely gratuitous from the point of view of the individual undergoing it as long as it is voluntarily accepted by him or her and - one presumes ${ }^{4}$ Maitzen would insist - as long as it is voluntarily accepted for the good reason that it is not gratuitous sub specie aeternitatis. Such justified evils then would be gratuitous vis a vis the individual undergoing them but non-gratuitous vis a vis the set of individuals of which the individual in question is a part. So, some evils ruled out by Jordan's/Stump's understanding of Theodical Individualism would be allowed by Maitzen's. The Theodicist will have an easier time of it if Maitzen is right. Is he? I think he is. Maitzen's concern to allow voluntariness to play this sort of role and thus deploy a more permissive version of Theodical Individualism seems wise in the light of examples such as the following.

Consider the case of a soldier in command of a platoon of men advancing through unsecured territory. The risks faced by the platoon as a whole would be minimised by his having one of his men walking quite a way out in front of the rest. By drawing any enemy fire that's to be had, treading on any landmines that might be on the path, and so

2 Stephen Maitzen, 'Ordinary Morality Implies Atheism', European Journal for Philosophy of Religion, 1. 2, (2009), p. 108.

${ }^{3}$ Maitzen, op. cit., p. 109.

${ }^{4}$ Indeed email correspondence with Maitzen on the first draft of this paper confirms this presumption. 
forth, this 'lead' soldier could reveal the whereabouts of risks prior to the rest of the platoon coming upon them. However, the role of lead soldier is one which, obviously, brings greater risks to the soldier occupying it than would fall on any individual soldier if the commander adopted the only alternative policy, having his men advance as a group. He explains all this to his men and one of them volunteers for the role. Being in full awareness of these facts, this man would, were the commander to take him up on his offer, be understandably more fearful as he advanced than he would be had the commander refused to accept his offer and they all advanced together. Even if in the end there were to turn out to be no enemy, landmines, and so forth and thus all the platoon arrived at their destination safely, that fear would be in itself an evil that the man in the lead position would have suffered and we may stipulate that it wouldn't bring him any greater good that in any way compensated him for it and that he couldn't have achieved in any other way. (For example, we may stipulate that his fellow soldiers would not applaud him for his heroism, but rather ridicule him for it.) Still, it seems, the soldier is noble in offering and the commander should accept his offer.

Let us suppose that the commander does accept this soldier's offer and the platoon starts on its journey and let us further suppose that in fact there are enemy lying in wait ready to spring an ambush. They act precipitously and shoot the lead soldier, thereby revealing their location; the rest of the platoon is thereby enabled to escape the ambush uninjured and reach their destination safely. The lead soldier's wound is painful, but he ultimately recovers from it. This soldier's suffering this wound then, we may suggest, would be an evil of quite a high order, one that would be gratuitous vis a vis him qua individual, though it would have brought a high order of net good - saving the lives of many fellow soldiers - to the group of which he was a part. Nevertheless, even had the commander known infallibly in advance of needing to decide whether or not to accept this soldier's offer that this is what would befall him, surely he would not have been obliged to refuse the offer. Indeed, we might go further and say that surely this knowledge would have made it all the more true that he should have done as he did: accept it. In general, whenever the net benefit that befalls the platoon outweighs the suffering of the individual who volunteers for the lead soldier position and could not have been achieved in any other way, the volunteer is courageous - not foolhardy 
- in volunteering and the commander, to the extent that we presume him to know of such things, is obliged to avail himself, and the rest of his platoon, of this man's bravery. In the light of examples such as this, Maitzen seems right to qualify Theodical Individualism as he does.

If we bring these thoughts together, we may therefore give Theodical Individualism a form which, whilst not being exactly that in which it has been supported by any of the authors of whom we've made mention, is more plausible than any we find in their writings. I therefore define Theodical Individualism as the following thesis.

Necessarily, God will not permit suffering that is

(a) undeserved;

(b) involuntary; and

(c) gratuitous vis a vis the individual suffering it, in the sense that it either does not produce a net benefit for that individual or, if it does produce a net benefit for him or her, is unnecessary in producing that net benefit. ${ }^{5}$

There are a number of grounds on which one might have doubts about Theodical Individualism even in this form and on which one might have doubts about other versions of it, such as Jordan's, Stump's and Maitzen's versions. ${ }^{6}$ Jordan and Maitzen give one of these grounds: combining it

${ }^{5}$ Careful readers will note that I have dropped 'human' from this formulation too; I presume that any Martians who, whilst not human are significantly similar to us in sentience, freedom, moral worth, and so on would, by Theodical Individualism, be exempt from suffering of this sort too. The same may not be true for non-human animals such as dogs. Nothing in this paper turns on these issues, so I leave them out of sight in the main text.

Gellman points out in discussion that it might be that an evil was gratuitous in my sense, yet still very easily justifiable, through being a necessary condition of a great enough good, whilst not producing it. He uses the following example. 'There could be cases (but not all!) where, for example, God allows a person to be sad so that another can make them very happy and cheer them up, stipulating that the cheer is so great that the person thinks it was very worthwhile to have been sad just to be so much cheered up! But of course the sadness does not produce the cheer but is only a necessary condition of it.'

${ }^{6}$ Some of the more general considerations which one might raise about whether God might, after all, permit some gratuitous evils could be employed here. See e.g. William Hasker, 'The Necessity of Gratuitous Evil,' Faith and Philosophy 9 (1992), p. 44; and Michael Peterson, Evil and the Christian God (Grand Rapids, 1982), chs. 4 and 5. 
(and things like it) with Theism undermines 'commonsense morality' Maitzen thinks Theodical Individualism obviously true and thus uses this incompatibility with commonsense morality as an argument for Atheism. But someone who finds Theism more plausible than Theodical Individualism would - presuming that they judge the existence of the sorts of evils in question; their incompatibility with Theodical Individualism; and the substance of commonsense morality as truths no less obvious than Maitzen judges them - simply run Maitzen's argument in reverse, taking him to have given them good reason to reject Theodical Individualism. ${ }^{7}$ (Hasker uses a similar incompatibility as an argument for God's allowing gratuitous evils in general. $)^{8}$ That's the direction in which I myself would incline to run Maitzen's argument. ${ }^{9}$ But, pushing

${ }^{7}$ Jerome Gellman has recently replied to Maitzen's paper ('On God, Suffering, and Theodical Individualism,' European Journal for Philosophy of Religion 1 (2010), pp. 187-191), accepting Maitzen's Theodical Individualism for the sake of argument, and challenging instead whether Maitzen's conclusion that 'we never have a moral obligation to prevent undeserved, involuntary human suffering' (187) follows from it. He advances some powerful arguments to the effect that it does not (though see Maitzen's reply in the same issue). Everything said in the current paper is, I think, compatible with Gellman's argument; in other words, it may well be as Gellman suggests, viz. that even if one did grant Theodical Individualism (which this paper suggests one should not do), one need not think that ordinary morality is threatened in the manner Maitzen and others would maintain (and in which I may seem to be supposing it is threatened in the main text). If that is so, then one doesn't have the 'running in reverse' reason to reject Theodical Individualism that I suggest in the main text, though of course that's hardly a comfort for Maitzen.

${ }^{8}$ Hasker, op. cit.

${ }^{9}$ I recall that I had a similar response when first reading Rowe's presentation of his evidential argument from evil. As is well known, Rowe gives a theological premise, that God wouldn't allow gratuitous evils, and a factual one, that there are gratuitous evils, and suggests that the second is the most controversial. He then spends his time in his paper defending the second premise, enthusing about a Moorean 'commonsense' approach, one which has as an element the propensity to run arguments in whichever direction preserves commonsense best, before concluding that (probably) God does not exist. When I first read his paper, it was the first - theological - premise that immediately struck me as the least obviously true, and I can remember being very surprised that he dealt with it in a few sentences. The theological premise is highly abstract, concerning how a perfectly morally good being - one significantly different from any of us in power and knowledge - would behave. It seemed far from obviously true to me, far less obviously true to me than at that stage Theism seemed to me. Thus, in precisely the spirit of Moore that Rowe encouraged, I read his argument as giving me reason to reject that premise. 
those sorts of considerations to one side, one could have doubts about Theodical Individualism based on grounds quite distant from any commitment to Theism, and it is some of those which I'll explore in this paper: in short, my argument will be that no principle similar to Theodical Individualism applies to us, so there is reason to think that Theodical Individualism does not apply to God.

II.

Let us go back to the example of the commanding officer seeking to get his men through potentially hostile territory with the minimum of loss and let us alter the situation slightly by supposing that, after he has explained the situation to his platoon, nobody volunteers to be the lead soldier. That seems quite reasonable, after all; it seems to be - and can be made obviously so by suitable accretion of detail - above and beyond the call of duty for any individual to put themselves forward for this dangerous role and it seems obviously contrary to each individual's own best interests (ante-mortem at least) for them to put themselves forward. If that is so, perhaps it is even in violation of a duty to themselves, if such things exist, or at least in violation of the demands of prudence, for anyone to volunteer, in which case a peculiar sort of 'impasse' threatens: each individually is only rational if they fail to volunteer, but nobody volunteering would lead to the group as a whole suffering more than any individual would suffer if he did volunteer. It seems obvious what the commanding officer should do: choose one soldier and order him to take the role. Of course there will be moral constraints operating on how the commanding officer chooses this soldier. These constraints will forbid him, for example, from choosing Private Uriah Hittite just because he happens to fancy Mrs Hittite and considers his chances with her would be improved were her husband to take this role. But there are morally innocent ways of making this selection: I take it that, failing anything else, one of these would be to get his men to draw lots. Let us suppose then that the commanding officer chooses one of his soldiers by this or some other morally innocent method and orders him forward. He will then be subjecting that soldier to an evil, at least the evil of the heightened fear of death or serious injury that inevitably accompanies being out in front. 
And indeed, whilst leaving verisimilitude in our suppositions as to the cognitive capacities of the commanding officer behind somewhat at this point, we can stipulate that the commanding officer will be subjecting this soldier to an evil of an infallibly-foreknown severe injury that will bring this individual soldier no net benefit. If we do so stipulate, it becomes all the more starkly obvious that this evil is one that is (a) undeserved, (b) involuntary, and (c) fails to bring a net benefit to the soldier concerned. Yet, as we make these stipulations it becomes no less obvious that the commanding officer should order a man forward. Sometimes indeed most of us will think - it is a commanding officer's duty to send one or more of his soldiers to what he is sure will be painful death, in other words to subject them to the most extreme form of undeserved, involuntary, and gratuitous (for them) evil of which we know..$^{10}$ And if all of this is so, then there are situations in which human agents are not under a moral constraint such as that which Theodical Individualism suggests God is under, which in turn suggests that we need positive reason to suppose that God is constrained in this way. The 'default', as it were, would be to assume that he is not.

Maitzen does not consider counterexamples drawn from the realm of created agents to principles akin to Theodical Individualism as undermining Theodical Individualism ${ }^{11}$ for he thinks that created agents are only excused from conforming to principles akin to Theodical Individualism in cases in which they are excused due to limitations of the sort that God would not suffer from. In the case we are imagining, for example, it seems very plausible that it is indeed a metaphysically contingent limitation on the commanding officer that excuses him from conforming to a principle akin to Theodical Individualism. Were the commanding officer to be able simply to click his fingers and thereby magically transport his platoon safely to their destination, obviously he

${ }^{10} \mathrm{I}$ have just returned from a short holiday in France and, whilst passing through Normandy, read on an information board beside the burnt-out Sherman tank in Ecouche the words of an Allied commanding officer to some of his men just before they went into battle: 'Between you and this nation lies a huge chasm. It is up to you to fill that chasm with your corpses.' History does not record whether they found this speech inspiring.

${ }^{11}$ I say 'akin to' as Theodical Individualism, by definition, applies only to God. If we are either to support or undermine it, we need to draw from examples of principles that are only 'akin to' it, in applying to created moral agents. 
should do that and not subject any soldier - volunteer or otherwise - to the risks attendant upon being lead soldier. Maitzen himself considers the example of quarantine and puts the point like this: 'These practices reflect our imperfection: it's only limitations in our knowledge and power (in this case, medical) that make us resort to triage or quarantine. We regret having to do it; we wish we had the resources to make these practices unnecessary. A perfect God, however, isn't subject to our limitations in knowledge or power, or indeed to any real limitations in knowledge or power. So no perfect God has an excuse for exploitation ['exploitation' is Maitzen's term for violating a principle such as Theodical Individualism] ${ }^{32}$ It seems then that Maitzen is willing to accept the general point that being unable to bring about some net good for a wider group without violating something akin to a Theodical Individualist constraint liberates one from such a constraint, sometimes at least. But if that general point is granted, then we cannot conclude that Theodical Individualism is true - that God is under such a constraint - until we know that there are no logical or metaphysical necessities which prevent him being able to bring about some net good for a wider group without violating Theodical Individualism. Sure, the constraint cannot be a metaphysically or logically contingent one, as it is in the case of the commanding officer, but that is no comfort for the defender of Theodical Individualism. For it is very plausible to suggest that there are metaphysical necessities of the sort that would liberate God. I have argued elsewhere (and I am hardly unique in doing so) that it is metaphysically impossible to create any set of libertarian significantly free creatures whose membership is greater than one whilst necessitating that they do not choose to subject one another to evils that are genuinely gratuitous. ${ }^{13}$ (There is an easy way of getting this result: define significant freedom in such a way that it requires of those who are significantly free that they can subject others

12 Stephen Maitzen, 'Does God destroy our duty of Compassion?', Free Inquiry, October/November (2010), p. 52.

${ }^{13}$ T. J. Mawson, Belief in God (Oxford: Oxford University Press, 2005), p. 198ff. This isn't, note, the 'hoary suggestion' Maitzen speaks of in his reply to Gellman ('On Gellman's Attempted Rescue,' EJPR 1 (2010), 1, 198), that God never interferes with our libertarian free will; that, obviously, would be too extreme a view. The view that is much more plausible and suffices here is that God sometimes rightly chooses to preserve the good of libertarian free will even when that free will is being used for bad ends. 
to such evils; any lesser degree of freedom just wouldn't be significant.) If moves of this sort are viable, then one has got reason to suppose that God is liberated from needing to conform to Theodical Individualism. ${ }^{14}$ This is a point to which we shall have occasion to return later.

So far my argument has rested heavily on an example, which - in not being of someone facing a logical or metaphysical impossibility - is not a perfect analogue for the situation in which God plausibly finds himself. It may also be objected to it that there are other issues in the background to my primary example which mislead us. For example, we have not yet specified that the soldiers were not volunteers for the army, even if not volunteers for the particular role of lead soldier. If they had volunteered for the army, then plausibly they would have done so knowing that a situation in which they'd then be commanded to take on extra personal suffering for the good of their comrades would be relatively likely to befall them. (That's the nature of army life, indeed corporate life in general.) We may suggest then that there is a sort of 'second-order' voluntariness in play in the example, one which allows the commanding officer to order one of them to take on the role of lead soldier. But we can stipulate otherwise - they are all conscripts - and we find our moral intuitions unaffected by such stipulations. Matters are similar for other features that might be supposed to be disanalogous and morally relevant; we can stipulate them away in our imagination and our intuitions that the commanding officer should violate a principle akin to that of Theodical Individualism remain strong. We have already been doing this by positing that the commanding officer has infallible knowledge of what will happen to the lead soldier - a serious injury rather than just knowledge of probabilities. Such stipulating away seems to make no difference to our moral intuitions. It is true that the soldier's constraints will remain contingent ones, but it is that they are constraints not that they are contingent constraints that liberates him from needing

\footnotetext{
${ }^{14}$ It may be that one's starting point with God - as the most perfect being possible should always be that there is not a limitation of a particular sort, but, even so, precisely as he is the most perfect being possible, impossibilities of a logical or metaphysical sort can impose limitations even on him. Such is the case I am suggesting here - or rather, as to articulate the reasons would require a whole new paper, such is something which we cannot assume is not the case, and we'd need to assume that it was not for Theodical Individualism to apply.
} 
to accord with any principle akin to Theodical Individualism. But I admit there are 'ineliminable' weaknesses to the analogy. As I have conceded, the relevant constraints are, after all, not ones of logical or metaphysical impossibility (they do just stem from his being unable to magic his platoon to their final destination - even the fact that he cannot make a soldier freely volunteer, which is a metaphysical constraint, is only cogent given that he's in the situation where he needs a volunteer). Other wrinkles could be ironed out by further epicycles of this example, but, rather than do that, I shall turn to an analogy even better for our purposes in thinking about the case of God, better in that it is a case where volunteering is more deeply impossible.

III.

Let us consider two potential parents deciding whether or not to have a child. It seems easy to specify things - e.g. that having a child would not be financially ruinous for this particular couple or prevent them from fulfilling their other obligations - so as to generate in our imaginations a situation in which the couple in question are neither obliged to have a child, nor obliged not to do so. We probably think that in fact most couples weighing whether or not to have children are not morally obliged in either direction. What is more, we can construct the situation so that we balance off all other goods in ways such that it will be neither overall good nor overall bad by any evaluative criterion for them either to have a child or to refrain from doing so. For example, we may stipulate that their circumstances are such that if they do not have a child, they will have more free time and money to pursue their other pastimes, pastimes which we may stipulate will then bring them exactly the same pleasure as having a child would have brought them. And so forth. Of course we may be worried, especially those of us who have had children, that this second sort of balancing off will be psychologically implausible for the vast majority of humanity, but the important point for our discussion is that it is that sort of worry that stops us from thinking that cases where there are no reasons on balance either to have or to fail to have a child are widespread. It is not the sort of worry I am about to outline, one that would be based on our endorsing a principle akin to Theodical Individualism. 
Every child born into this world is one whom the parents can be almost certain will suffer evils that are undeserved, involuntary, and gratuitous at the very least vis a vis the individual. (A prime example of such a widespread evil would be bullying, which almost every child suffers from at some stage in his or her life.) It is very plausible to suppose when contemplating whether or not to have children that any child born will be such as to suffer evils of this sort - ones that are undeserved, involuntary and gratuitous vis a vis the child. But, even so, we do not think that we are thereby more or less universally placed under an obligation not to have children. We then are not under a constraint akin to the Theodical Individualist one when it comes to our acts of procreation. Why think that God would be under such a constraint when it came to his act of creation? I can't think of any reason.

The problem with defending any variant of Theodical Individualism seems to me to lie in the fact that in some cases it just is obviously permissible (parents), indeed in some cases it is obviously obligatory (commanding officers), for people to subject other people to undeserved and involuntary suffering which is gratuitous vis a vis the individual. Clear cases are those where that suffering is known to be non-gratuitous vis a vis some larger group and relatively small in comparison to the benefits that befall that larger group as a result and that could not have been achieved in any other way. The 'could not have been be achieved in any other way' is - for created agents - often in part a result of limitations that they suffer from and which God would not suffer from, e.g. being unable to magic soldiers over potentially hostile territory by clicking one's fingers. But if the 'could not' was generated by a logical or metaphysical impossibility, e.g. being unable to force a particular soldier to volunteer, for volunteering needs to be done freely in a libertarian sense, that does not seem to alter its cogency: it is still a 'could not' that may liberate one from needing to accord with a principle akin to Theodical lndividualism. In cases where the suffering is known to be non-gratuitous vis a vis some larger group, such sufferers will then perhaps ${ }^{15}$ be being used by whomever subjects them to the suffering as means to an end, but, even if so, they need not be used merely as means to an end, i.e. used as means

${ }^{15}$ I say 'perhaps' as it may be that the relevant suffering is foreseen but unintended in the mind of the person subjecting them to it, which perhaps stops them using the other even as a means. 
in a way which is morally problematic. (We all think it is permissible to use people as means. E.g. when phoning one's credit card company, one uses whomever - eventually - picks up the phone as a means to the end of rectifying their latest error. What is not permissible is using someone merely as a means, e.g. venting one's anger on that hapless employee for the failings of some unidentifiable co-worker by swearing at him or her.) One way in which one can avoid using people merely as means, i.e. as means in a way that is morally impermissible, is by those people volunteering for the role of means in advance of being put in it (thus, the cases on which Maitzen focuses). But that - it seems to me - is only one way. Consider the following situation.

A couple's first child suffers from a disease which is such that he needs a bone marrow donation if he is to survive into adulthood; otherwise, he will die a premature and painful death. The only sort of person who could be, even in principle, a suitable donor would be another child born to the same parents, though any other child conceived by them would be suitable for being a donor. The process of donating bone marrow is a painful one for the donor and would have to be undergone by the donor child within a few months of his or her birth for the marrow to be suitable for transfer into the first child. The parents had been considering having another child anyway and had found all other considerations, pro and con, balanced against one another. They now know that if they have a second child, he or she could be valuable as a means to the end of healing their first child. Is it morally permissible for them to add this reason into the balance in their thinking? Is it even obligatory for them to do so? ${ }^{16}$

In my experience, intuitions differ on these questions. Personally, I think that the situation can be filled out in such a way that it becomes very plausibly obligatory on the parents to try to conceive another child.

${ }^{16}$ If you think that any consideration of how the second child could be a means to some good end for the first child is morally impermissible, then you should in consistency think that parents who know that if they have children past the first, these subsequent children will provide playmates for the first act impermissibly when they bear that in mind in deciding whether or not to have subsequent children. But that seems absurd. In most non-Western cultures, the idea that it was morally impermissible to consider, when deciding how many children to have, how one's children might help one in one's old age would strike people as equally absurd. 
But what is less controversial and sufficient for our present purposes is that it be at the least permissible for them to have a second child in part so as to be able to use this second child as a means to the end of saving the life of their first. Let us add in some further details to suggest this then.

The parents know that they will love this second child for his or her own self, not merely as a means to the end of saving their first child. They know that, acting from their love (and being fortunately circumstanced in other ways), they can and will give this second child a life that is much better than simply overall good; they will give the second child a superfluity of goods in the widest sense of 'goods.' These goods will be such that they more than provide adequate compensation for the pain that the child would undergo during the operation, which is to say that they'll be such that were the child to have been presented with the choice of no operation but none of these goods or this amount of suffering plus these goods in advance of being subjected to the operation (as was of course impossible), he or she would have been acting against his or her own self-interest if he or she had not chosen to undergo the operation. Of course they intend to subject this second child to a painful operation at a stage in the child's life where it cannot understand what is happening to it; the suffering they intend knowingly to bring on the child ${ }^{17}$ will be undeserved, involuntary, and bring the child suffering it no benefit at all (the goods they later give it - those which are in fact more than adequate compensation - they do not give just because they are compensation; they give them unconditionally, because they love this second child and are able to give him or her these goods; so the second child would have got these goods anyway). But the parents intend, when the second child is old enough to understand, to explain why it is they allowed him or her to be subjected to this suffering. And we may posit that the parents know that this point of time will more or less coincide with one from which the child, looking back, can see that he or she has a life which is overall more than merely good; by that time enough of those compensating goods will have been given to him or her (though, as just mentioned, not given to him or her just because they compensate

${ }^{17}$ Again it is a 'nice question' whether they intend the suffering or merely foresee it as an inescapable feature of what they do intend and whether this makes a difference. 
for his or her earlier suffering), for him or her retrospectively to endorse his or her parents' decision to use him or her so as to benefit the brother who by then he or she will love every bit as much as the parents do. It seems to me that it is at the least permissible for parents of whom all of this is true to have the second child in part for the reason that he or she will be able to benefit the first; this is so even though the benefit which the second child provides to the first is not necessary for that second child to achieve some net benefit - the goods which, as it is, if the parents do subject the second child to the operation, may be spoken of as more than adequate compensation, would have come to him or her had the parents conceived him or her but then decided not to subject him or her to the operation necessary to save his or her sibling's life (though they would not then have come to him or her as compensation). Thus, parents who knew they were in such a situation would not be required to avoid subjecting an individual, the second child, to suffering that is (a) undeserved by the individual undergoing it, (b) involuntary for that individual (at least at the time he or she undergoes it), and (c) gratuitous vis a vis that individual. Thus, a fortiori given that God would know with all the more certainty in virtue of his omniscience that he was in a similar situation were he ever to be so, we cannot conclude that God is required to avoid subjecting an individual to suffering that is (a) undeserved by the individual undergoing it, (b) involuntary for that individual (at least ante-mortem), and (c) gratuitous vis a vis that individual. There may well be some goods which can of metaphysical necessity only be achieved by subjecting individuals to suffering of this sort and which are good enough to justify God in doing so. ${ }^{18}$

Maitzen considers by contrast the following case: 'Imagine that I clone a child into existence ... and imagine that I treat the child splendidly for all but the final minute of his or her life. But during that final minute, I allow someone to abuse the child to death in order to show onlookers just how revolting child abuse is and thereby deter them from ever abusing a child .... I behave imperfectly, to say the least ${ }^{19}$ Here, Maitzen is surely right; it would be impermissible for one to use one's clone in this fashion.

${ }^{18}$ As already mentioned, I discuss this further in my Belief in God (Oxford: Oxford University Press, 2005), 198ff.

${ }^{19}$ Maitzen, 'Does God destroy our duty of Compassion?', p. 53. 
However, I would suggest that something along the lines of Maitzen's cloning case might be morally permissible. It seems to me that for such exploitation, to use Maitzen's term, to be morally permissible, it would need to involve oneself (as exploiter) having knowledge of the fact that the exploited will volunteer (even if only retrospectively [which point may only be reached post-mortem in the case of God, of course] and only after compensation has been paid to him or her [which point again might be only post-mortem for God]) to be exploited in this way. In addition, it seems to me that it would need to involve oneself having the ability and intention to provide that compensation (and knowledge of the fact that one will provide it [again, this might be post-mortem for God]). Maitzen's case doesn't meet these conditions. But cases along the lines of Maitzen's where created agents meet these conditions can be constructed, even if, in constructing such cases, one has to stipulate - somewhat implausibly - that the participants have been given knowledge of a higher degree of certainty than we usually have. And I don't have the same response to them as to Maitzen's. Suppose, for example, you generate a clone in the manner Maitzen suggests. It now transpires that you could allow this clone, whilst a child, to be used in the horrible way Maitzen mentions; he would be tortured severely (albeit not to death) so as to make the point about how bad it is to torture children more vividly than it would be possible to make that point in any other way. Suppose further that you know that net good of a high order can only come from your making this point this vividly. But you also know that this high-order good will come from your making this point this vividly. We may posit, for example, that you know that if and only if you do so exploit your child, will it be that three other children will not be tortured to death (and tortured in an equally painful way). This then is to posit that you know that the torture will be non-gratuitous from this wider perspective. Finally, you know that you'll thereafter - when your child grows up into adulthood - be able to explain to him why you had to use him in this way if you were to bring about this high order of net good; and you know you'll by then have given him what he regards as compensation (i.e. goods which he'll rightly judge outweigh in goodness the badness of what he suffered), so that his life is overall a good to him (though the torture segment of it wasn't of course; it was genuinely gratuitous vis a vis himself). It seems to me that in such a circumstance it would be morally permissible for you 
to exploit your clone in Maitzen's sense. ${ }^{20}$ In fact, my intuitions suggest that it would be obligatory, but I shall not push that stronger claim for it is unnecessary in this context.

In correspondence Maitzen suggests that we ask ourselves when considering such cases the following question; "In ideal circumstances, would we use the means that these agents are using?" [and suggests that] the answer is "No, but these agents aren't in ideal circumstances." $\mathrm{He}$ says that he would 'need to be convinced that God also faces unavoidably non-ideal circumstances, and for reasons I give in the original article I don't think that the libertarian freedom theodicy is convincing on that score.' However, were the 'non-ideal' circumstances that God was in circumstances of logical/metaphysical necessity, then there would be no more ideal circumstance even possible. Thus again we may return to the point that we cannot conclude that Theodical Individualism is true - that God's under such a constraint - until we know that there are no logical or metaphysical necessities which prevent him being able to bring about some net good for a wider group without violating Theodical Individualism, a modality of a different order - not just some physical impossibility, for example, but a metaphysical one - but one that nevertheless places him in a situation akin to his only being able to stop three children being tortured to death by allowing one to be tortured severely. And it is very plausible that there are metaphysical necessities of this sort. For, as already mentioned, it is very plausible to suggest that it is metaphysically impossible to create any set of libertarian significantly free creatures whose membership is greater than one whilst necessitating that they do not choose to subject one another to evils that are genuinely gratuitous and that libertarian significant freedom is a significant good.

In this connection it is helpful to look at Alston's position as discussed in a footnote to Maitzen's original article and described by Maitzen there as 'a bit complicated. ${ }^{21}$ Maitzen suggests that Alston's view involves 'a combination of willingly borne undeserved suffering and adequately

\footnotetext{
${ }^{20}$ Interestingly, Gellman reports that his intuitions are precisely the reverse. One might say that one thing is for sure then: supposing various charitable things about the virtues of Gellman, Maitzen, Swinburne, and myself, intuitions in this area are not reliable. Even if that were so, it would obviously be of no help to Maitzen-type arguments, as they rely on our intuitions being reliable.

${ }^{21}$ Maitzen, 'Ordinary Morality Implies Atheism,' p. 109.
} 
compensated undeserved suffering. Because the suffering willingly bears her suffering (at least retrospectively), I don't believe that Alson's position conflicts with TI [Theodical Individualism] as formulated here.' So, it seems that Maitzen would count any suffering which in some postmortem state is 'retrospectively willingly borne' as being voluntarily assented to and thus not a sort of suffering which God is, via Theodical Individualism, compelled to avoid anyone suffering.

Maitzen's seems like an odd use of the notion of voluntariness to me. In the case of a second child being conceived so as to be able to save a first, the fact that the second child will at some later stage 'retrospectively willingly bear' the suffering that accompanies the operation by which he or she saved his or her sibling's life does not make the suffering that the second child undergoes at the time of that operation any more voluntary. I would incline then to say that suffering that is not voluntarily assented to at the time it is suffered is not voluntary. Some of it may yet not be strictly involuntary (if we take involuntary to be contrary to the will), for it may be simply non-voluntary in that it is so minor that the person suffering it doesn't form a will to avoid it. But some of it will be genuinely involuntary at the time in that it will be contrary to a formed will at that time; it stays an instance of genuinely involuntary suffering even if in retrospect one 'willingly' bears it. However, I would maintain, contra Maitzen I take it, that at least the sort of involuntary suffering that is later voluntarily consented to rationally is morally justifiable. And I'd have read Alston as suggesting something along these lines too. If we do stick with Maitzen's extended notion of 'voluntary', such that something is voluntary just if it is at some stage (any stage, however fleetingly? / in a 'final analysis' / at an all-things-considered stage?) voluntarily consented to, then it becomes obvious that we are never (prior to the Eschaton that is) in a position to judge that the world does contain instances of suffering that are involuntary. For any instance of suffering to be involuntary, on Theism it'd have to be the case that at the end of time it wasn't 'retrospectively willingly borne' by its resurrected bearer and who would wish to suggest we can see this fact with any clarity? Indeed, a Universalist about salvation might contend that on Theism we know in advance that there will be no cases of involuntary suffering in this sense. ${ }^{22}$ And this would be a result

${ }^{22}$ As I put it elsewhere, 'On Theism, as we have seen [I have previously argued 
very undesirable from Maitzen's point of view as he requires it to be the case that instances of suffering of the sort Theodical Individualism rules out do indeed knowably occur. Maitzen's argument then is at that stage best served by the sense of voluntariness that I prefer, where it is sufficient for something to be involuntary that it is unwillingly borne - in the sense of contrary to the will - at the time it is borne (and which hence enables us definitely to know that some instances of suffering are involuntary prior to the Eschaton). However, what this gives Maitzen's argument with one hand it takes away with the other, in that it is then - I would contend - not at all obvious that underserved involuntary suffering of the sort that brings the sufferer no net benefit is always impermissible, as Theodical Individualism suggests. Indeed, cases of commanding officers choosing one of their soldiers for roles that result in their severe injury or death; parents having children; parents having children in part so as to use those children as means to other worthy ends; and so on, suggest to me that we are sometimes obligated to subject individuals to suffering that is undeserved, involuntary and brings the individual concerned no net benefit (indeed sometimes no benefit at all, other perhaps than the dubious 'benefit of being of benefit to someone else').

In order to drive the moral home, I want to labour a little bit more a variation of the thought experiment concerning parents deciding whether or not to have a second child in part to save the life of their first. Let us suppose then that the parents conceive a second child in part with the intention of using this second child so as to be able to save their first. And they give birth to a healthy girl, someone who would be a suitable donor. However, when the time comes, the parents choose not to go through with subjecting the girl, the second child, to the operation. Perhaps they are impressed by the fact that they cannot get her voluntary assent to the procedure in advance of subjecting her to it and think that this disbars them from subjecting her to it. So it is that the two

Theism entails Universalism], after our finite lives here an infinite life awaits us hereafter. For every creature who suffers, there will come a day when they say that as individuals their suffering has been more than adequately compensated for and on which they will be able to see how their suffering fitted into a greater whole that was overall worth it. On that day, even those who were broken on the wheels of the machine as they turned will thank God for it.' That, I take it, is their 'retrospectively willingly bearing it'. T. J. Mawson, Belief in God (Oxford: Oxford University Press, 2005), p. 215. 
siblings grow up together, the first in increasingly bad health, the second receiving all the goods that would have come to her had she undergone the operation and then would have been in part truly described as compensating goods. The second child is thus the net benefiter - she didn't in the end have to undergo the suffering of the operation and she has a life which is in all other respects as good as she'd have had if she'd had the operation. The first child is obviously the net loser and a net loser by a larger amount than the second child benefits - he dies an early and painful death. As the boy heads towards his premature and painful death, the parents explain to the girl how it is that she would have been able to save her brother had she been operated on at an earlier stage and they explain how it is that they chose not to subject her to such an operation and how it is that it is now too late for any such operation to be effective; they must just all watch this first child die.

In such a case, it seems to me that the second child could truly say to the parents that they had failed in their duty to the first child. But, what is more, it also seems to me that the second child could maintain that the parents had failed in their duty to her. The parents ought to have subjected the second child to the operation for the first child's sake in part because the second child had a right to be of use to her brother, which right the parents have not dutifully honoured and, in not dutifully honouring it, they have wronged the second child. At the time the decision had to be made, the second child was too young to know about it, so only the parents could have made it the case that she would save her sibling's life; the parents denied the second child the honour of saving her sibling's life and thus as well as wronging the first child the parents have wronged the second child. This is perhaps slightly puzzling. How can the parents have wronged the second child by failing to impose upon her an evil that in itself would bring her no benefit? One way of resolving this puzzlement would be to acknowledge that the very fact of being of value to someone else (at least significant value to someone one loves) is itself a benefit to the person who is of value. Swinburne speaks in this vein more generally of the benefit of 'being of use' and it may be that one characterizes this situation best by saying that in this case a benefit of being of use would have been so great for the second child as to make the second child actually - contrary to our supposition in setting the situation out - a net benefiter from her undergoing the 
operation. Be that as it may, we can see, I suggest, that sometimes one actually honours an individual more by doing that which brings them no benefit (other than the 'benefit of being a benefit to somebody else,' if we may speak of such) and certainly no net benefit, and that sometimes people would have more to complain of on their own behalves were one not to so honour them, even in situations where they would be the net benefiters of one's not so honouring them.

\section{IV.}

In conclusion, examples of situations which, even if not everyday, are ones the elements of which are hardly beyond the bounds of our experience suggest that agents may, without deviating from morality's demands, permit or indeed knowingly cause suffering that is (a) undeserved by the individual undergoing it, (b) involuntary for that individual (at the time it is being suffered), and (c) gratuitous vis a vis that individual. The examples concern created agents, agents then who - by the nature of the case - will be under limitations that God is not under and it is often plausible that they are justified in behaving as they do only because they are under these limitations. However, God's omnipotence is not usually thought of as allowing him to do the logically or metaphysically impossible, so 'limitations' (the word now needs scare quotation marks as these are not really limitations at all) arising from these areas would similarly mean that he was not morally constrained in the way Theodical Individualism suggests. That is to say that, contrary to Theodical Individualism, God may well permit suffering that is (a) undeserved by the individual undergoing it, (b) involuntary for that individual (at least ante-mortem), and (c) gratuitous vis a vis that individual. A clear case of permissible suffering that meets these conditions would be one where the suffering, whilst undeserved by the individual undergoing it, would nevertheless be one that it would be rational for the individual to acquiesce to (even if only post-mortem, after adequate compensation had been provided to him or her and the place of this suffering in a wider scheme of things that was overall good and in which it was not gratuitous had been made clear). From that post-mortem vantage point, the sufferer might regard his or her being subjected to this suffering as an honour in the way 
that it is an honour to be chosen to lead one's platoon through enemy territory or to undergo a painful operation that saves one's brother's life, even if such honours might not be capable of being regarded as such ante-mortem. Even if the sufferer did not regard the suffering as being a 'benefit' (the benefit of being of benefit to someone else) which outweighed the suffering and thus did regard it as something that he or she would have net-benefitted from God's having prevented, the sufferer may, in consistency with this judgement, regard it as something which God would have wronged him or her in preventing, for honour is more important than maximal benefit in such cases.

We all recognise the childish error of the 'Whoever dies with the most toys wins' approach to life. What I am suggesting is that it may be as erroneous to suggest that 'Whoever has maximal goods over his or her total (ante- and post-mortem) life has done best.' (Were that to be so, then perhaps a person who received less goods than he or she could have got would have a cause for complaint against any person who could have arranged for him or her to get more.) But if what makes a life go well for the person living it is in part that they be of use to others, a life in which they are so of use - even if by being of use they are not the net benefiter - could be a better life for them than the alternative and they'd then have more reason for complaint if someone denied them the opportunity to be so of use so as to maximise their goods. Sometimes at least, having the honour of being of use makes one's life better for oneself than it would have been had one got the greater goods that one would otherwise have received at the expense of being of use. Thus Theodical Individualism is false and any arguments which utilize it are unsound. ${ }^{23}$

${ }^{23}$ I am grateful to Steve Maitzen for his comments on a draft of his paper and for his discussion of various wider issues, not all of which I have been able to address in the final version of it. I am also grateful for the comments of Jerome Gellman and Richard Swinburne on the penultimate draft. 